\title{
Diagnostic Challenge of Acute Appendicitis: Appraisal Through Alvarado Score
}

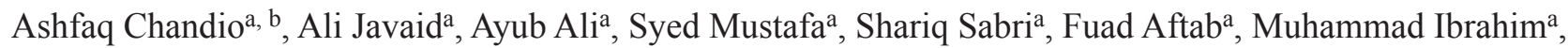 \\ Syed Naqvi ${ }^{\mathrm{a}}$
}

\begin{abstract}
Background: Acute appendicitis is a common surgical emergency which, even with modern diagnostic facilities, remains a challenging task for the surgeon. The variations in presentation pertaining to time, signs and symptoms can baffle even the very experienced surgeons. The aim of the study was to find out the predictive value of the Alvarado scoring system in diagnosis of acute appendicitis and its clinical applicability.
\end{abstract}

Methods: A total of 113 patients admitted through casualty in MidWestern General Hospital, Ennis between January and November 2006 with right lower quadrant pain were analyzed prospectively for possible diagnosis of acute appendicitis in the light of Alvarado scoring system, which comprises of signs, symptoms and laboratory findings which are graded individually and divided into four broad groups, namely unlikely ( 1 - 4), possible (5 - 6), probable (7 - 8), and very probable $(9-10)$. Chi-square test was done to establish the relationship of histological diagnosis with scoring system.

Results: Out of 113 patients, there were 67 males and 46 females with a mean age of 25.04 years $\pm 14.21 \mathrm{SD}(7-81)$. The Alvarado scoring was found to be $85 \%$ accurate for unlikely group, $60 \%$ for possible group, $83 \%$ for probable group and $100 \%$ for very probable group (P $=0.0001)$.

Conclusion: Alvarado scoring system is simple, fast, reliable and easy to use and may increase diagnostic certainty of clinical examination in diagnosis of acute appendicitis.

Keywords: Appendix Alvarado score; Diagnosis; Appendicitis; Appraisal

Manuscript accepted for publication November 13, 2014

aDepartment of General and Laparoscopic Surgery, Mid-Western Regional Hospital, Ennis, Co. Clare, Ireland Republic

${ }^{b}$ Corresponding Author: Ashfaq Chandio, Department of General and Laparoscopic Surgery, Mid-Western Regional Hospital, Ennis, Co. Clare, Ireland Republic. Email: chandioashfaq@yahoo.com

doi: http://dx.doi.org/10.14740/jcs244e

\section{Introduction}

Acute appendicitis is a common surgical emergency which, even with modern diagnostic facilities, remains a challenging task for the surgeon. The variations in presentation and the variability of signs and symptoms of acute appendicitis can baffle even the very experienced surgeons. Widespread research has been undertaken to diagnose this common surgical emergency more precisely. Amongst several methods of diagnosing acute appendicitis, Alvarado scoring system has been acknowledged as a standard for more than two decades [1]. The accuracy and applicability has been a matter of debate and has been challenged by some authors [2].

The Alvarado score is a 10-point scoring system which is based on clinical signs and symptoms and lab investigations [1] (Table 1).

In modified Alvarado scoring, "shift to the left of neutrophil maturation" is not included.

\section{Aim}

The aim of our study was to find out the predictive value of the

Table 1. Alvarado Scoring System

\begin{tabular}{ll}
\hline Features & Score \\
\hline Symptoms & \\
$\quad$ Migratory right iliac fossa pain & 1 \\
Nausa/vomiting & 1 \\
$\quad$ Anorexia & 1 \\
Signs & 2 \\
$\quad$ Right iliac fossa tenderness & 1 \\
$\quad$ Fever $>37.3{ }^{\circ} \mathrm{C}$ & 1 \\
$\quad$ Rebound pain in right iliac fossa & \\
Laboratory test & 2 \\
$\quad$ Leucocytosis $\left(>10 \times 10^{9} / \mathrm{L}\right)$ & 1 \\
$\quad$ Neutrophilic shift to the left $>75 \%$ & 10 \\
$\quad$ Total score &
\end{tabular}


Table 2. Probability of Alvarado Score

\begin{tabular}{lllll}
\hline & Frequency & Percent & Valid percent & Cumulative percent \\
\hline Unlikely & 23 & 20.4 & 20.4 & 20.4 \\
Possible & 29 & 25.7 & 25.7 & 46.0 \\
Probable & 46 & 40.7 & 40.7 & 86.7 \\
Very probable & 15 & 13.3 & 13.3 & 100.0 \\
\hline
\end{tabular}

Alvarado scoring system in diagnosis of acute appendicitis and its clinical applicability.

\section{Patients and Methods}

A total of 113 patients admitted through casualty in Mid-Western Regional Hospital, Ennis between January and November 2006 with right lower quadrant pain were analyzed prospectively for a possible diagnosis of acute appendicitis in the light of Alvarado scoring system, which comprises of signs, symptoms and laboratory findings which are graded individually and divided into four broad groups, namely unlikely (1 - 4), possible $(5-6)$, probable $(7-8)$, and very probable $(9-10)$ (Table 2 ). Data were recorded onto a spread sheet (Microsoft(r) Excel 2002, Seattle, WA, USA) conceding different ways of analysis and tabulations and appropriate statistical analysis was performed on SPSS (Version 14). Chi-square test was done to establish the relationship of histological diagnosis with scoring system.

\section{Results}

Out of 113 patients, there were 67 males and 46 females. The mean age was found to be 25.04 years \pm 14.21 SD $(7-81)$. Migration of pain to the right iliac fossa was found in 55 patients, accounting for about $48.7 \%$. Sixty-seven patients gave a history of anorexia accounting for $59.3 \%$.

On clinical examination, 112 patients $(99.1 \%)$ had tenderness in the right iliac fossa, with 46 of them having rebound tenderness. Fever was associated in only 33 patients and raised WBC count was seen in 69 patients.

All patients underwent surgery with open appendicectomy in 102 patients and the rest through laparoscopic approach, numbering 11 .

Histological examination proclaimed 78 cases to be inflamed while the rest, 35 being normal (Table 3). The Alvarado scoring was found to be $85 \%$ accurate for unlikely group,
$60 \%$ accurate for possible group, $83 \%$ accurate for probable group and $100 \%$ accurate for very probable group $(\mathrm{P}=0.0001)$ (Table 4).

\section{Discussion}

Acute appendicitis is a clinical diagnosis with expected life time risk of about 7\% [3]. Currently it is likely more hospital systems order CT or US prior to evaluation, $95 \%$ accuracy of CT scan whereas ultrasonography has sensitivity of $90 \%$ and specificity of $80-90 \%$ in diagnosing acute appendicitis. Alvarado scoring system can be safely used by general practitioners in deciding the need for referral to A\&E. Presently patients are either referred lately or unnecessarily due to the lack of competency to make an appropriate diagnosis [4]. In a study by England and Crabbe, they mentioned about the difficulty in diagnosing appendicitis in children who were treated with antibiotics as the clinical picture changes [5]. Cope wrote "Diagnosis of appendicitis is usually easy but there are difficulties which need to be discussed" [6]; the study portrays the use of Alvarado scoring system in patients with suspected acute appendicitis which contributes a high degree of sensitivity and specificity. The scoring relies mainly on clinical history, examination, and a few simple investigations. Hoffman et al found that diagnostic aids can dramatically reduce the number of negative appendicectomies, appendicular perforations, and the duration of stay in hospital [7]. Ovarian pathologies on the side also give a similar clinical picture and hence a high negative appendicectomy rate in women of childbearing age. West et al compared the predictive value of ultrasonography and leucocytes, and found that ultrasonography had a better predictive value but both investigations had limited utility as preoperative diagnostic tools $[8,9]$. In doubtful cases, repeat clinical assessment and graded compression ultrasonography may yield more valuable information to ascertain the need for surgery [10]. Right iliac fossa pain with guarding, accompanied by fever and elevated white blood cell counts, was found to be predictive of appendicitis in most cases [11]. In 1975,

Table 3. Histology

\begin{tabular}{|c|c|c|c|c|c|}
\hline \multirow{2}{*}{ Count } & \multicolumn{5}{|c|}{ Alvarado gps } \\
\hline & Unlikely & Possible & Probable & Very probable & Total \\
\hline Normal & 20 & 8 & 7 & 0 & 35 \\
\hline Inflamed & 3 & 20 & 41 & 14 & 78 \\
\hline Total & 23 & 28 & 48 & 14 & 113 \\
\hline
\end{tabular}


Table 4. Evaluation of Alvarado Score

\begin{tabular}{llll}
\hline Alvarado score & No. of patients & Inflamed appendix & Normal appendix \\
\hline $1-4$ & 23 & 3 & 20 \\
$5-6$ & 28 & 20 & 8 \\
$7-8$ & 48 & 41 & 7 \\
$9-10$ & 14 & 14 & 0 \\
Total & 113 & 78 & 35 \\
\hline
\end{tabular}

White et al stated that repeat assessment in the hospital setting reduced unnecessary appendicectomies from $20 \%$ to $6 \%$ [12]. In his original paper, Alvarado recommended surgery for patients with a score of 7 or more and observed patients with scores less than 6 [1]. It has been shown that diagnostic accuracy increases from $58 \%$ to $71 \%$ when clinical scoring systems are used by junior staff [13]. A drop of 50\% in perforation rates has been shown in some reports, while no reduction has been noted in other studies $[13,14]$. Dado et al in 2000 did a study in children and concluded that a clinical scoring system could reduce the rate of unnecessary surgery by aiding early clinical diagnosis of appendicitis [15]. In most appendicectomies, the naked eye examination of appendix quite often confirms the diagnosis, but at times a normal looking appendix may be reported as one with chronic appendicitis on histological examination. Hence histological report is taken as the final word in diagnosis of acute appendicitis.

In our study, we found that there is a male predominance for appendicitis which correlates with findings of similar studies [16].

\section{Conclusion}

Alvarado scoring system is simple, fast, reliable and easy to use. It may increase diagnostic certainty of clinical examination of acute appendicitis. We recommend that this tool should be used especially by the General Practioners and Junior Doctors in their practice and generally by every surgeon.

\section{Disclosure}

No financial support received and no conflicts of interest to declare.

\section{References}

1. Alvarado A. A practical score for the early diagnosis of acute appendicitis. Ann Emerg Med. 1986;15(5):557564.

2. Owen TD, Williams H, Stiff G, Jenkinson LR, Rees BI. Evaluation of the Alvarado score in acute appendicitis. J R Soc Med. 1992;85(2):87-88.

3. Ergul E. Importance of family history and genetics for the prediction of acute appendicitis. Internet $\mathrm{J}$ surg.
2007;10:2.

4. Bergeron E, Richer B, Gharib R, Giard A. Appendicitis is a place for clinical judgement. Am J Surg. 1999; 177(6):460-462.

5. England RJ, Crabbe DC. Delayed diagnosis of appendicitis in children treated with antibiotics. Pediatr Surg Int. 2006;22(6):541-545.

6. Cope Z. The early diagnosis of the acute abdomen. 14th ed. London: Oxford University Press; 1972.

7. Hoffmann J, Rasmussen OO. Aids in the diagnosis of acute appendicitis. Br J Surg. 1989;76(8):774-779.

8. West WM, Brady-West DC, McDonald AH, Hanchard B, Fearon-Boothe D. Ultrasound and white blood cell counts in suspected acute appendicitis. West Indian Med J. 2006;55(2):100-102.

9. Coleman C, Thompson JE, Jr., Bennion RS, Schmit PJ. White blood cell count is a poor predictor of severity of disease in the diagnosis of appendicitis. Am Surg. 1998;64(10):983-985.

10. Rice HE, Arbesman M, Martin DJ, Brown RL, Gollin G, Gilbert JC, Caty MG, et al. Does early ultrasonography affect management of pediatric appendicitis? A prospective analysis. J Pediatr Surg. 1999;34(5):754-758; discussion 758-759.

11. Arfa N, Gharbi L, Marsaoui L, Ben Rhouma S, Farhati S, Bougamra S, Mannai S, et al. [Value of admission for observation in the management of acute abdominal right iliac fossa pain. Prospective study of 205 cases]. Presse Med. 2006;35(3 Pt 1):393-398.

12. White JJ, Santillana M, Haller JA, Jr. Intensive in-hospital observation: a safe way to decrease unnecessary appendectomy. Am Surg. 1975;41(12):793-798.

13. McAdam WA, Brock BM, Armitage T, Davenport P, Chan M, de Dombal FT. Twelve years' experience of computeraided diagnosis in a district general hospital. Ann R Coll Surg Engl. 1990;72(2):140-146.

14. Adams ID, Chan M, Clifford PC, Cooke WM, Dallos V, de Dombal FT, Edwards MH, et al. Computer aided diagnosis of acute abdominal pain: a multicentre study. $\mathrm{Br}$ Med J (Clin Res Ed). 1986;293(6550):800-804.

15. Dado G, Anania G, Baccarani U, Marcotti E, Donini A, Risaliti A, Pasqualucci A, et al. Application of a clinical score for the diagnosis of acute appendicitis in childhood: a retrospective analysis of 197 patients. J Pediatr Surg. 2000;35(9):1320-1322.

16. Meade RH. The Evolution of Surgery for Appendicitis. Surgery. 1964;55:741-752. 